Cell compatible, site-specific covalent modification of hydrogel scaffolds enable dynamic control over cell-material interactions

Joshua A. Hammer, Anna Ruta, Aidan M. Therien, and Jennifer L. West, Ph.D.

Number of pages (including cover page): 6

Number of figures: 5 
RGDS-mCherry-SpyCatcher-6His-TEV-FlagTag-43370.5 MW

$\rightarrow$ RGDS $\rightarrow$ mCherry

RGDSGSGSMVSKGEEDNMAIIKEFMRFKVHMEGSVNGHEFEIEGEGEGRPYEGTQT

AKLKVTKGGPLPFAWDILSPQFMYGSKAYVKHPADIPDYLKLSFPEGFKWERVMNFE

DGGVVTVTQDSSLQDGEFIYKVKLRGTNFPSDGPVMQKKTMGWEASSERMYPEDG

ALKGEIKQRLKLKDGGHYDAEVKTTYKAKKPVQLPGAYNVNIKLDITSHNEDYTIVEQ

YERAEGRHSTGGMDELYKGSGSMVDTLSGLSSEQGQSGDMTIEEDSATHIKFSKRDE

DGKELAGATMELRDSSGKTISTWISDGQVKDFYLYPGKYTFVETAAPD GYEVATAITFT VNEQGQVTVNGKATKGDAHIGGSGGSHHHHHHGGENLYFQGGRDYKDDDDK

Figure S1: Amino acid sequence of RGDS-SC, with relevant domains annotated. RDGS-SC was identical to RGDS-SC, with the exception of the N-terminus which bore the non-adhesive RDGS sequence in place of the adhesive RGDS ligand. 


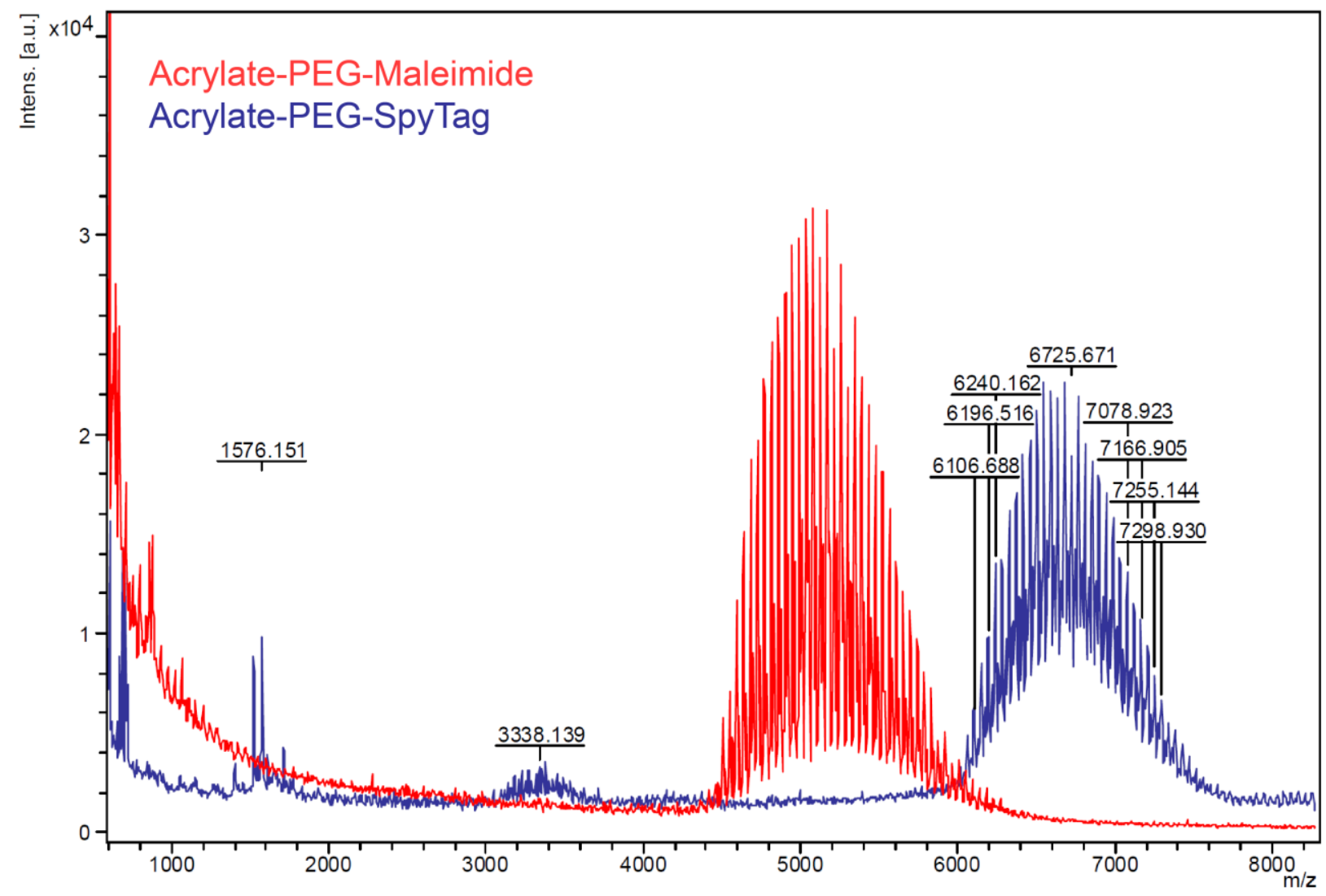

Figure S2: MALDI spectra of acrylate-PEG-maleimide before and after conjugation with SpyTag. 
$100 \mu \mathrm{M}$ SpyTag

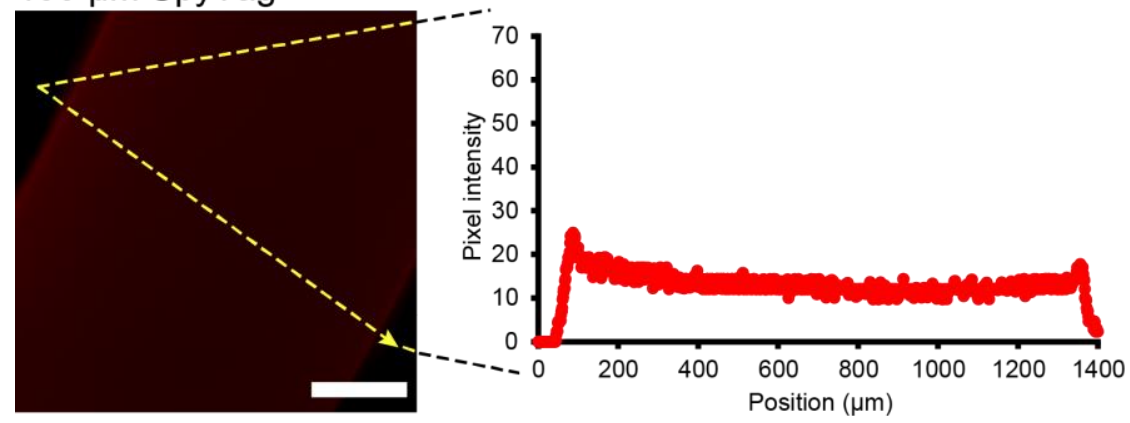

\section{M SpyTag}

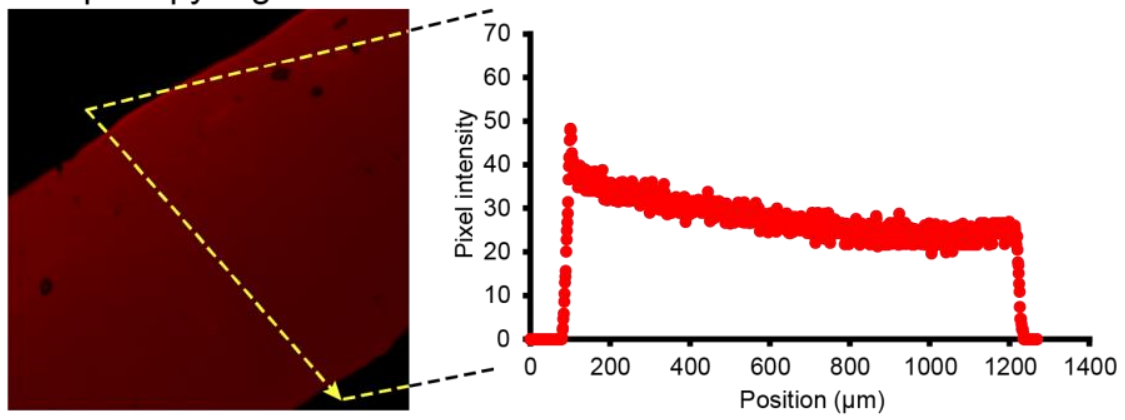

$400 \mu \mathrm{M}$ SpyTag

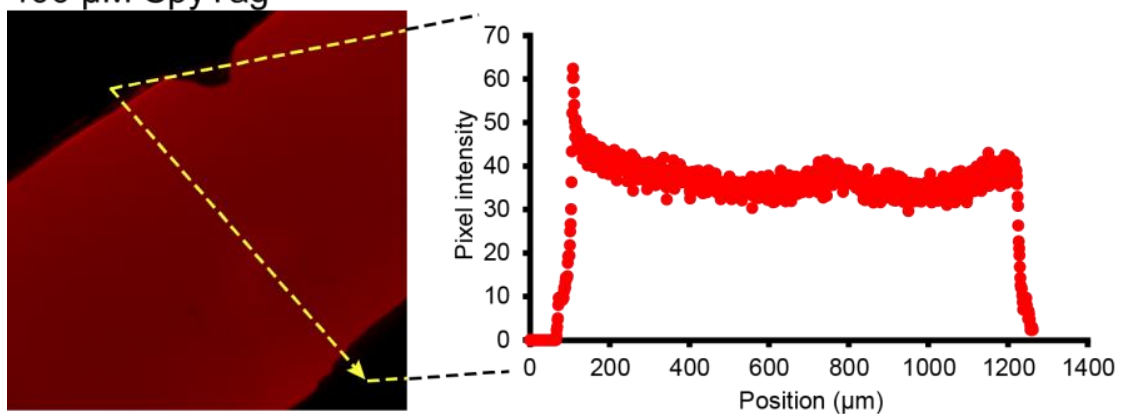

Figure S3: Fluorescent profiles of RGDS-SC-labeled gels presented in figure 3. Images were analyzed using ImageJ. Scale bar is $100 \mu \mathrm{m}$. 


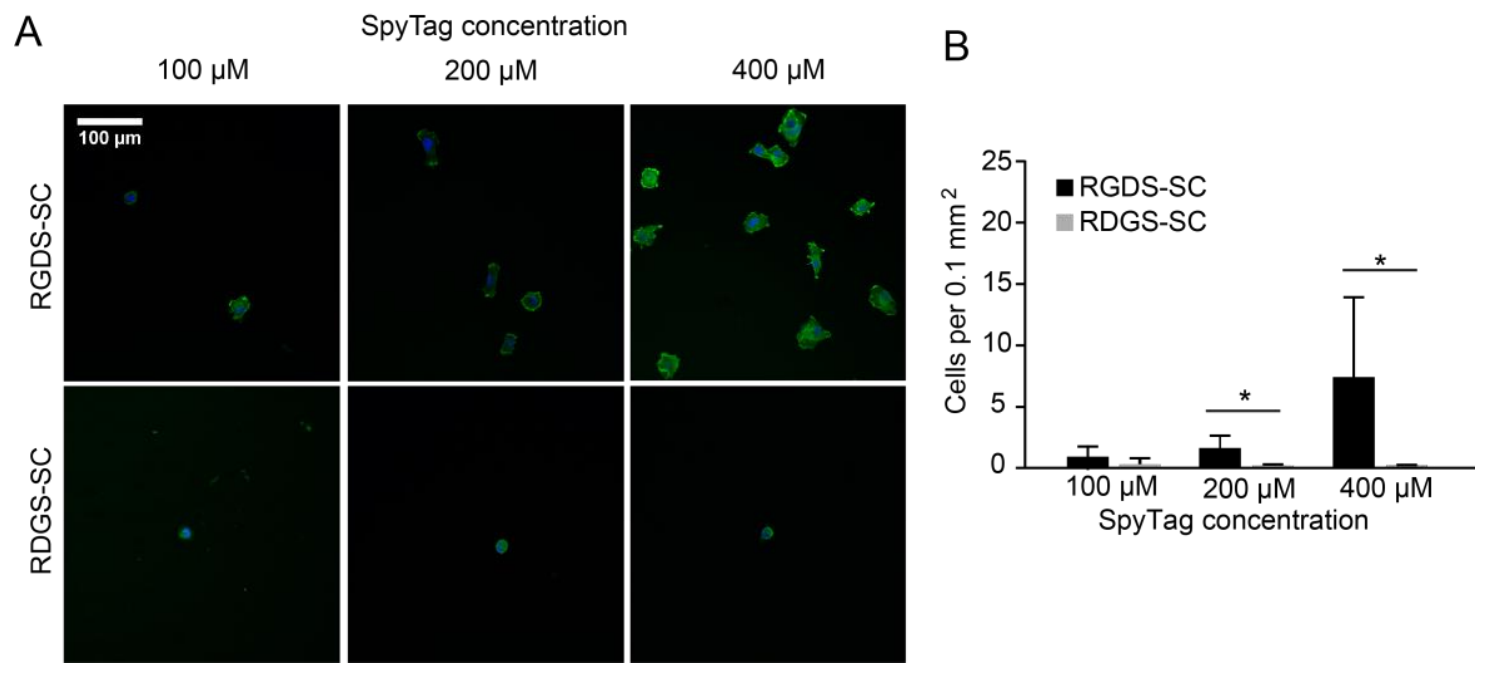

Figure S4: RGDS-SC-presenting gels supported 3 T3 fibroblast attachment and spreading within 90 minutes of seeding. A) Fluorescent images of 3 T3 fibroblasts 90 minutes after seeding on either RGDS-SC-labeled gels or RDGS-SC-labeled gels. Images captured using a Zeiss 780 upright confocal microscope equipped with a 20x water dipping objective. Green: phalloidin-AF488 (factin). Blue: DAPI (nucleus). B) Adhered cell quantification was conducted by counting nuclei in epifluorescent micrographs taken using a 10x objective. Each condition contained 3 gels, and 2 fields of view (FOV) per gel were analyzed. Statistics were conducted using two-way ANOVA to confirm differences across all groups $(p<0.05)$, followed by a Student's t-test within each SpyTag condition. $*=\mathrm{p}<0.05$, indicating a significant difference. 

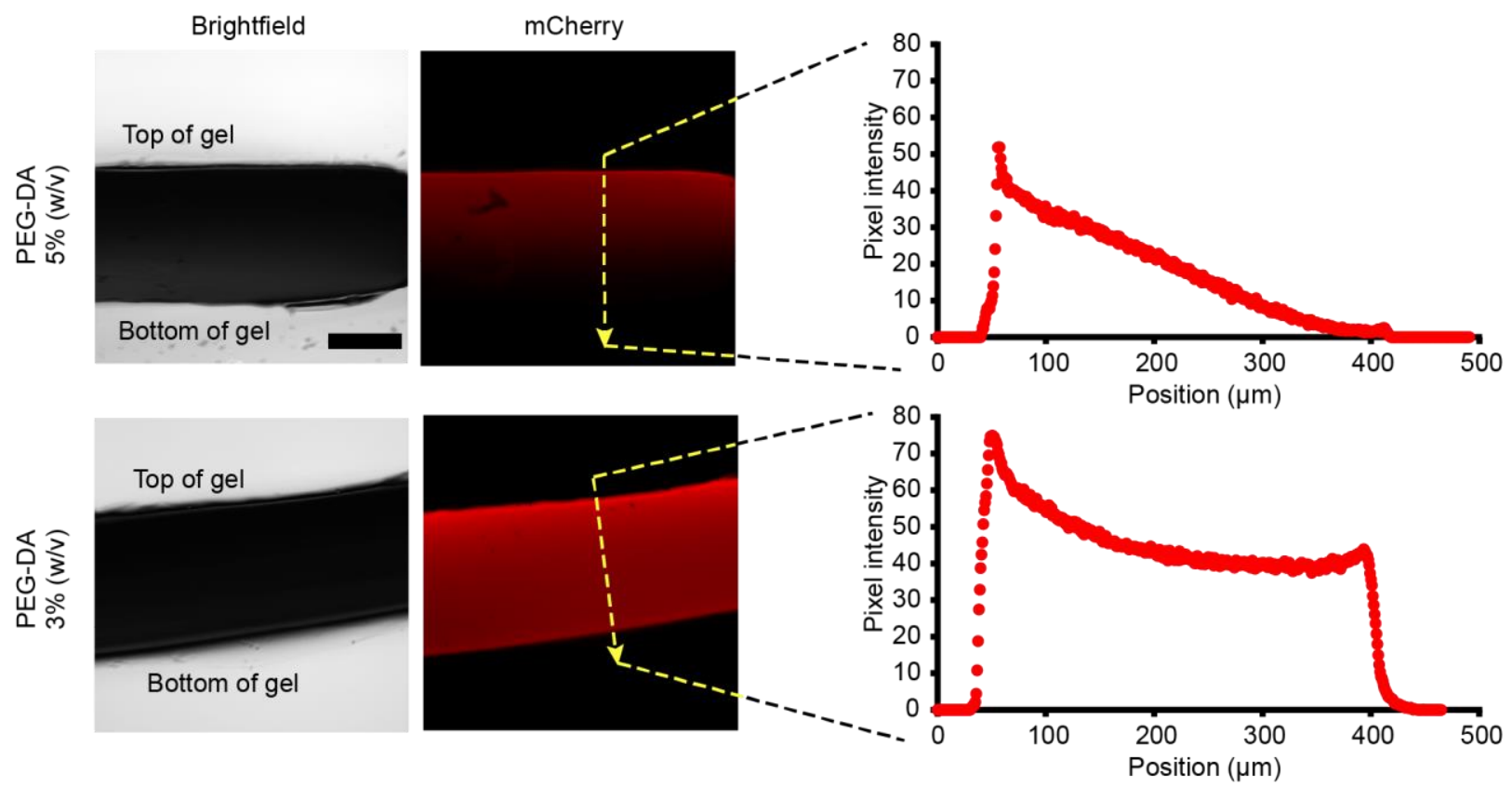

Figure S5: Fluorescent profiles of PEG-DA gels containing $2 \mathrm{mM}$ SpyTag after $2 \mathrm{hrs}$ in $200 \mu \mathrm{M}$ RGDS-SC in cell media. SpyCatcher-mediated hydrogel labeling proceeded in the presence of bovine calf serum $(10 \%)$ at $37{ }^{\circ} \mathrm{C}$. The lower density PEG hydrogel was more permissive to diffusing RGDS-SC, as indicated by fluorescent profile. Images were collected using a Zeiss 880 confocal microscope. Scale bar is $200 \mu \mathrm{m}$. 